\title{
New Biochemical Parameters in the Differential Diagnosis of Ascitic Fluids
}

\author{
Anabela Angeleria, c , Adriana Rocher ${ }^{\mathrm{a}}$, Beatriz Caracciolo ${ }^{\mathrm{b}}$, Marcela Pandolfo ${ }^{\mathrm{b}}$, Luis Palaoro ${ }^{\mathrm{a}}$, \\ Beatriz Perazzi ${ }^{\mathrm{b}}$
}

\begin{abstract}
Background: In the cases of ascitis, it is essential to determine their origin using the parameters obtained by the cytological and biochemical examinations. The aim of this study was to evaluate the usefulness of different biochemical markers and the number of cells in the differential diagnosis of ascitic fluid (AF).

Methods: One hundred ninety-one cases of AF were studied, who were admitted to the hospital from January 01, 2009 to December 31, 2014. One hundred fifty-two of them were included in the analysis, and the remaining 39 were excluded because they had more than one associated pathology, clotted or hemolyzed.
\end{abstract}

Results: The more frequent etiologies of AF were the cirrhosis (29\%), the infections (22\%) and the neoplasies (19\%). Other pathologies reached $16 \%$. Cutoff $>300$ cells $/ \mathrm{mm}^{3}$ detected the $78 \%$ of exudates. The AF/serum (S) of aspartate aminotransferase (AST) (>0.5), lactate dehydrogenase $(\mathrm{LDH})(>0.6)$, proteins $(\mathrm{PT})(>0.5)$, cholesterol $(\mathrm{COL})(>0.4)$, and alanine aminotransferase (ALT) $(>0.5)$ correctly detected $80 \%, 78 \%, 72 \%, 70 \%$ and $70 \%$ of the exudates, respectively.

Conclusion: We proposed the utilization of a new cutoff of cellular counting, major of $300 / \mathrm{mm}^{3}$, since it would allow improving the detection of exudate ascites, without including the transudate ascites. AST AF/serum ratio (AF/S) showed the major usefulness in the differentiation and characterization of $\mathrm{AF}$; $\mathrm{LDH}$, proteins, cholesterol and ALT might be also acceptable in the above mentioned differentiation. The serum-ascites albumin gradient (SAAG) turned out to be a good marker of portal hypertension associated with cirrhotic processes. Creatine kinase (CK), alkaline phosphatase (ALP), amylase (AMI), total bilirubin (TB), triglycerides (TG) and glucose (GLU) did not allow differentiating exudates from transudates.

Manuscript accepted for publication February 26, 2016

${ }^{a}$ Cytology Laboratory, Department of Clinical Biochemistry, Clinical Hospital, University of Buenos Aires, Argentina

${ }^{b}$ Chemistry Laboratory, Department of Clinical Biochemistry, Clinical Hospital, University of Buenos Aires, Argentina

${ }^{\mathrm{c} C}$ Corresponding Author: Anabela Angeleri, Cytology Laboratory, Department of Clinical Biochemistry, Clinical Hospital, University of Buenos Aires, Argentina. Email: anabela.angeleri@yahoo.com.ar

doi: http://dx.doi.org/10.14740/gr700w
Keywords: Biochemical parameter; Cell count; Ascitic fluids; Aspartate aminotransferase

\section{Introduction}

Ascites is the pathological accumulation of fluid in the peritoneal cavity. The classification of the fluid as exudates or transudate is the first step in the evaluation of its etiology. The liquid is generally a transudate in patients with acute or chronic liver failure, massive liver metastases, hypoalbuminemia, or congestive heart failure, while in cases such as carcinomatosis, bacterial peritonitis, or pancreatitis, it is an exudate [1].

The diagnostic paracentesis should be routinely performed in patients with recent-onset ascites, those requiring hospitalization due to stroke and those with ascites and unexplained clinical deterioration [2].

Traditionally, the exudate-transudate concept was based on the protein concentration of ascitic fluid (AF) for classifying peritoneal exudates [3]. Different levels of protein in the AF have been suggested as cutoffs for identifying exudates, ranging from 25 to $30 \mathrm{~g} / \mathrm{L}$.

The use of this single biochemical parameter erroneously classifies many exudates originating in infectious or tumors as transudates, while some transudates in cirrhosis and congestive heart failure may be classified as exudates due to high protein levels [4].

Boyer et al used an adaptation of light criteria $[5,6]$ for differentiating between transudates and exudates in AF using the concentration of protein and lactic dehydrogenase (LDH) levels as well as the ratio of these values between the serum and $\mathrm{AF}[7]$.

The difference between the albumin concentration between serum and AF, called serum-ascites albumin gradient (SAAG), reflects directly and indirectly the colloid osmotic pressure and the degree of portal hypertension [8]. Pare et al [9] suggested that SAAG is a better discriminator of portal hypertension than protein concentration in AF.

Patients with ascites related to portal hypertension have $\mathrm{SAAG} \geq 1.1 \mathrm{~g} / \mathrm{dL}$ (transudates) and in those with ascites whose portal pressure is normal, SAAG is $\leq 1.1 \mathrm{~g} / \mathrm{dL}$ (exudates) [4, 9-11].

Moreover, with regard to cellularity, in the literature, a 
Table 1. Ascitic Etiologies

\begin{tabular}{|cl}
\hline Causes & Patients (\%) \\
\hline Exudates & $83(55 \%)$ \\
Infectious diseases & $34(22 \%)$ \\
Neoplasms & $29(19 \%)$ \\
Paraneoplastic effusions & $19(12 \%)$ \\
\hline Gastric adenocarcinomas & 8 \\
Lymphomas & 7 \\
Colon adenocarcinoma & 2 \\
Esophagus adenocarcinoma & 2 \\
Neoplastic effusions & $10(7 \%)$ \\
Lymphomas & 3 \\
Gastric adenocarcinomas & $3(1$ Pap inconclusive, AgNOR $>14)$ \\
Testicular germ cell carcinoma & 1 \\
Ovary adenocarcinoma & 1 \\
Renal clear cells carcinoma & 1 \\
Breast carcinoma & $1(1$ Pap inconclusive, AgNOR $>14)$ \\
Transudates & $69(45 \%)$ \\
Heart failure & $6(4 \%)$ \\
Oirrhosis & $45(29 \%)$ \\
\hline
\end{tabular}

cutoff of $>1,000$ cells $/ \mathrm{mm}^{3}$ is used to classify AF as exudates [5]. The mechanisms that contribute to the malignant ascites include obstruction related to tumor lymphatic drainage, increasing the capillary permeability and activation of the reninangiotensin-aldosterone system, producing neoplastic fluids and metalloproteinases which degrade the extracellular matrix [12]. The cytology has a high specificity for the detection of neoplastic cells in effusions; the sensitivity varies from $40 \%$ to $90 \%[13,14]$.

The aim of this study was to evaluate the usefulness of different cutoffs applied to the cellularity and biochemical markers (metabolic and enzymatic markers) in the differential diagnosis of AF. To the best of our knowledge, it is the first report about the value of aspartate aminotransferase (AST) and the cellular counting for differentiating between exudates and transudates.

\section{Materials and Methods}

We studied 191 samples from patients with AF, who were admitted to the hospital from January 01, 2009 to December 31,2014 . One hundred fifty-two of them were included in the analysis, and the remaining 39 where excluded because they had more than one associated pathology, clotted or hemolyzed. The categorization of transudates or exudates was determined according to the patient's pathology. Cell count was performed by duplicate as total cells $/ \mathrm{mm}^{3}$ in a hemocytometer, directly or diluted with saline or Turk solution for liquids with plenty of cells or bleeding smears.

The differential count was performed with the Giemsa method, counting a minimum of 200 cells; when the smears were suspicious for malignant cells, the Papanicolaou (Pap) stain was used to confirm the diagnosis of malignancy. In cases of inconclusive cytology, the AgNOR technique was used (Argyrophilic nucleolar organizer region).

Simultaneous determinations were performed in AF and serum (S) of the following biochemical parameters: glucose $(\mathrm{GLU})$, proteins (PT), albumin (ALB), cholesterol (COL),

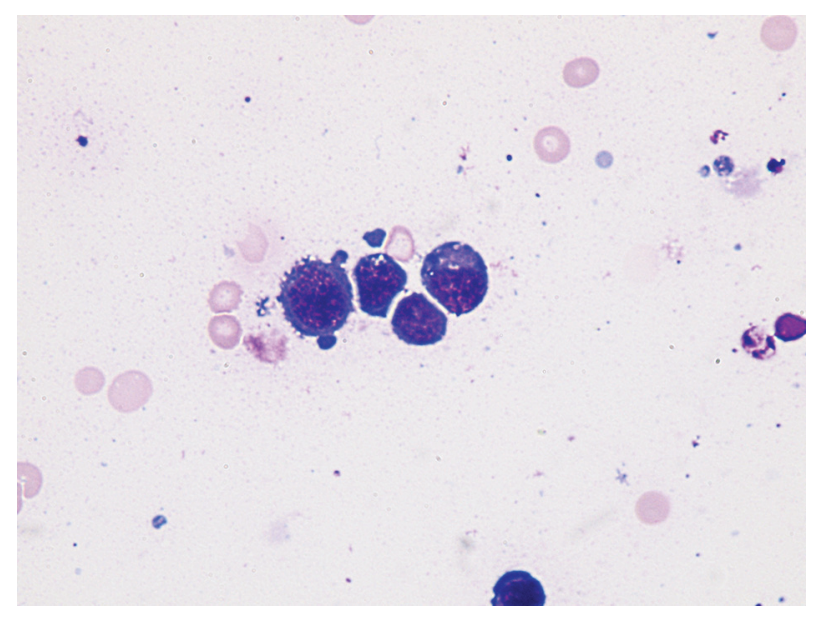

Figure 1. Immature lymphoid cells appearance (plasmablastic lymphoma involving stomach). Giemsa stain, × 1,000. 


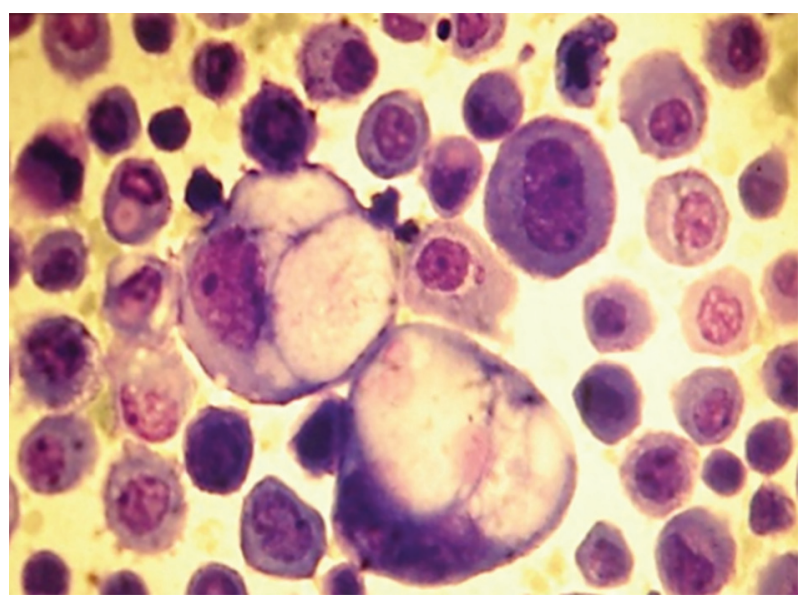

Figure 2. Isolates neoplastic cells (gastric adenocarcinoma). Ascitic fluid. Giemsa stain, × 400 .

triglycerides (TG), LDH, creatine kinase (CK), alanine aminotransferase (ALT), AST, alkaline phosphatase (ALP), amylase (AMI) and total bilirubin (TB). The methods used are recommended internationally. We used a Hitachi Autoanalyzer 917 (Roche).

The diagnosis of malignant ascites required cytology or peritoneal biopsy. Spontaneous bacterial peritonitis was diagnosed by the presence of a counting of neutrophils $>250 / \mathrm{mm}^{3}$ or by microbiological positive cultures.

The diagnosis of tuberculous peritonitis required positive culture of the AF for Mycobacterium tuberculosis or the presence of granulomas in peritoneal biopsy in the absence of other causes for granulomatosis.

Liver cirrhosis was diagnosed by the combination of impaired liver function tests, evidence of portal hypertension or liver biopsy. The diagnosis of congestive heart failure was performed using clinical criteria and echocardiographic evidence of ventricular dysfunction.

Our study was carried out according to the principles of Declaration of Helsinki for research in human subjects [15].

The usefulness of cellularity and each biochemical parameter for identifying exudates was evaluated in terms of sensitivity, specificity and efficiency.

\section{Statistical analysis}

Yates-corrected Chi-square $\left(\chi^{2}\right)$ analyses and Fisher method were used to detect statistically significant differences. A value

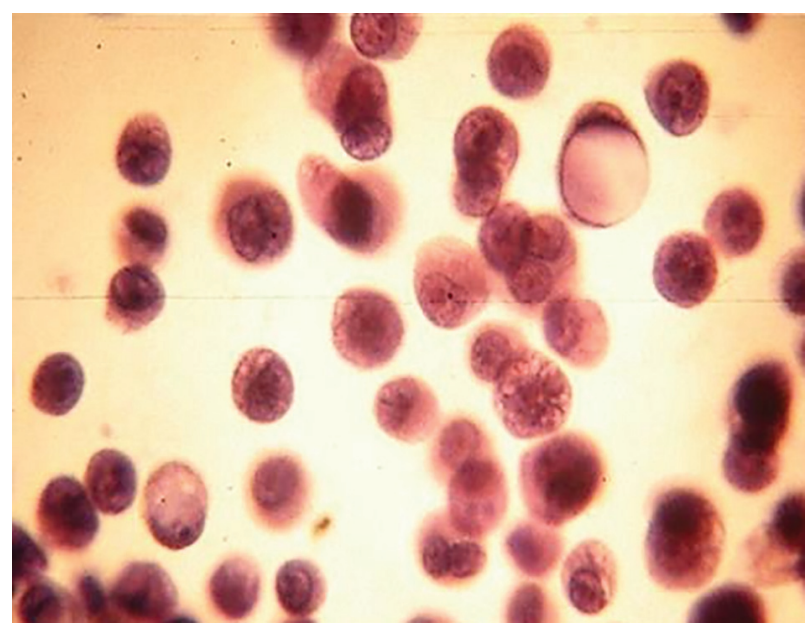

Figure 3. Isolates neoplastic cells (gastric adenocarcinoma). Ascitic fluid. PAP stain, $\times 400$.

of $\mathrm{P} \leq 0.05$ was considered statistically significant.

\section{Results}

Of the 152 samples studied, 83 (55\%) were exudates and 69 $(45 \%)$ were transudates. The etiologies of $\mathrm{AF}$ are shown in Table 1. The more frequent etiologies in exudate ascites were infectious (22\%) and malignant (19\%); from these last groups, $12 \%$ corresponded to paraneoplastic effusions and $7 \%$ to malignant effusions. The malignant cells were detected in the fluid (Pap and Giemsa stains) in 7/10 neoplastic AF (70\%). The most frequent metastatic cancers were lymphoma (Fig. 1) and stomach adenocarcinoma (Figs. 2 and 3). In two patients (one stomach adenocarcinoma and one breast carcinoma), the results of the Giemsa and Pap stains were "inconclusive" but the application of the AgNOR technique confirmed the diagnosis of malignancy, reaching a value $>14$ (values of number of NOR dots for malignant cells in body fluids: $13.78 \pm 3.89$ ) [16], increasing the sensitivity to $90 \%$. Other metastases detected were one testicular germ cell carcinoma and one renal clear cell carcinoma.

The most common cause of transudates was cirrhosis (29\%); $4 \%$ of the transudates were related to heart failure, and other pathologies reached $12 \%$ of the total of patients.

The percentages of patients with transudates and exudates related to cellularity and biochemical parameters are shown in Table 2, and sensitivity, specificity and efficiency for each

Table 2. Percentage of Patients With Transudates and Exudates Related to Cellularity and Biochemical Parameters

\begin{tabular}{|c|c|c|c|c|c|c|c|c|}
\hline & $\begin{array}{l}>300 \text { cells/ } \\
\mathrm{mm}^{3}, \mathrm{n}(\%)\end{array}$ & $\begin{array}{l}>500 \text { cells/ } \\
\mathrm{mm}^{3}, \mathrm{n}(\%)\end{array}$ & $\begin{array}{l}\text { PT AF/S > } \\
0.5, n(\%)\end{array}$ & $\begin{array}{l}\text { COL AF/S > } \\
0.4, \text { n (\%) }\end{array}$ & $\begin{array}{l}\text { AST AF/S > } \\
0.5, \text { n (\%) }\end{array}$ & $\begin{array}{l}\text { LDH AF/S > } \\
0.6, n(\%)\end{array}$ & $\begin{array}{l}\text { ALT AF/S > } \\
0.5, \mathrm{n}(\%)\end{array}$ & $\begin{array}{l}\text { SAAG }< \\
1.1, \text { n }(\%)\end{array}$ \\
\hline$E(n=83)$ & $65(78)$ & $47(57)$ & $60(72)$ & $58(70)$ & $66(80)$ & $65(78)$ & $58(70)$ & $34(41)$ \\
\hline $\mathrm{T}(\mathrm{n}=69)$ & $2(3)$ & $0(0)$ & $12(17)$ & $10(15)$ & $10(15)$ & $7(10)$ & $13(19)$ & $61(88)$ \\
\hline$P$ value & $<0.0001$ & $<0.0001$ & $<0.0001$ & $<0.0001$ & $<0.0001$ & $<0.0001$ & 0.0001 & $<0.0001$ \\
\hline
\end{tabular}

T: transudate; E: exudate; SAAG: serum-ascites albumin gradient. 
Table 3. Sensitivity, Specificity and Efficiency for Each Biochemical Parameter

\begin{tabular}{lllll}
\hline Proposed parameter & Sensitivity $\mathbf{( \% )}$ & Specificity $(\mathbf{\%})$ & Efficiency $(\%)$ & P \\
\hline$>300$ cells $/ \mathrm{mm}^{3}$ & 78 & 97 & 85 & $<0.0001$ \\
$>500$ cells $/ \mathrm{mm}^{3}$ & 57 & 100 & 79 & $<0.0001$ \\
AST AF/S $>0.5$ & 80 & 85 & 81 & $<0.0001$ \\
LDH AF/S $>0.6$ & 78 & 90 & 83 & $<0.0001$ \\
PT AF/S $>0.5$ & 72 & 85 & 78 & $<0.0001$ \\
COL AF $/ S>0.4$ & 70 & 85 & 75 & $<0.0001$ \\
ALT AF $/ \mathrm{S}>0.5$ & 70 & 81 & 74 & 0.0001 \\
\hline
\end{tabular}

biochemical parameter are shown in Table 3.

Forty-seven of the 83 exudates $(57 \%)$ were detected using the traditional cutoff for cell count greater than $500 / \mathrm{mm}^{3}$, but using the cutoff proposed in the present paper $\left(300\right.$ cells $\left./ \mathrm{mm}^{3}\right)$, the detection increased to $65 / 83(78 \%)$. Of the biochemical parameters studied, the AST ratio AF/S $(>0.5)$ detected the greater number of exudates correctly classified $66 / 83(80 \%)$, while 10 of $69(15 \%)$ transudates were falsely classified.

The AF/S of LDH $(>0.6)$, PT $(>0.5), \mathrm{COL}(>0.4)$, and ALT $(>0.5)$ correctly detected $78 \%, 72 \%, 70 \%$, and $70 \%$ of the exudates, respectively. The SAAG $(\geq 1.1 \mathrm{~g} / \mathrm{dL})$ detected correctly 60/68 (88\%) transudates. AMI (>100 IU/L) and GLU $(<60 \mathrm{mg} / \mathrm{dL})$ detected correctly only $7 \%$ and $3 \%$ of the exudates, respectively.

FAL, BT, CK, AMI, GLU, and TG did not allow differentiating exudates from transudates.

\section{Discussion}

Abdominal paracentesis, with careful fluid analysis, is the first step in the evaluation of ascites. The literature continues to report a cutoff of $>500$ cells $/ \mathrm{mm}^{3}$ to classify AF as exudate [7]. This paper proposes to reduce the cutoff to $300 / \mathrm{mm}^{3}$ in AFs, since the detection of exudates is increased by $21 \%$ without affecting the number of incorrectly classified transudates, obtaining a sensitivity of $78 \%$ and an efficiency of $97 \%$.

The sensitivity of cytology to detect malignant cells in serous effusions varies between $40 \%$ and $90 \%$ according to the recent literature [12-14]. The high frequency of false negatives (over $70 \%$ ) is mainly due to sampling error, and to a lesser extent, to a misinterpretation of study material [13]. In this study, $10 \%$ of the AFs were of malignant origin and the sensitivity of cytology in the detection of neoplastic cells was high $(70 \%)$. However, no false positives were detected, consistent with the low frequency described in the literature, in which reports are produced by an excessive interpretation of a reactive atypia [17]. Spontaneous bacterial peritonitis (SBP) is defined by a cell count of more than 250 neutrophil cells $/ \mathrm{mm}^{3}$, as by a positive culture of the AF. However, the role that biochemical parameters play for such differentiation is controversial.

In this paper, the $\mathrm{AF} / \mathrm{S}>0.5$ for $\mathrm{AST}$ and $>0.6$ for $\mathrm{LDH}$ were the most helpful in the diagnosis of exudate, with a sensitivity of $80 \%$ and $78 \%$ and efficiency of $85 \%$ and $90 \%$, respectively for the both parameters. There are no references in the literature concerning the AST as a marker of differentiation between exudates and transudates. We suggest that the observed increase of AST in exudate ascites could be attributed to an increase in the number of cells in these processes, together with an increased cell destruction which would bring about the release of the enzyme from an intracellular localization.

Another parameter that was useful in the differentiation between exudates and transudates was the AF/S ratio of $\mathrm{PT}$ $>0.5$, with sensitivity and efficiency of $72 \%$ and $85 \%$, respectively; this parameter erroneously classified the fluids as transudates in a low percentage of the cases (15\%). Moreover, the AF/S ratio for ALT $(>0.5)$ and $\operatorname{COL}(>0.4)$ could also be useful in the differentiation of the fluids, though less than the aforementioned parameters, as detected $70 \%$ of the exudates with an efficiency of $81 \%$ and $85 \%$, respectively. Concerning COL and PT, although there are controversies in the literature, some authors have described that $\mathrm{AF} / \mathrm{S}$ for $\mathrm{PT}<0.5$ and $\mathrm{COL}<$ $55 \mathrm{mg} / \mathrm{dL}$ may aid in the diagnosis of cirrhotic process with efficiency of 94\% [2, 18]. Boyer et al [7] had defined an exudate ascites as one that met at least two of the following criteria: $\mathrm{AF} / \mathrm{S} \geq 0.5$ for PT; $\mathrm{AF} / \mathrm{S} \geq 0.6$ for $\mathrm{LDH}$ and $\mathrm{LDH} \geq 400 \mathrm{IU} / \mathrm{L}$. Also, Rana et al [19] reported that COL levels over $70 \mathrm{mg} / \mathrm{dL}$ are related to the origin of malignant ascites, with a specificity of $100 \%$ and efficiency of $94 \%$.

SAAG was a good marker of portal hypertension associated mainly with cirrhosis, as described by the literature, as it is recommended as a marker to differentiate ascites caused by portal hypertension from other causes of ascites, with an efficiency $>90 \%[11,18,20,21]$. TB was not useful in characterizing the AF unlike some authors that reported a sensitivity and specificity of $72 \%$ and $86 \%$, respectively [22]. GLU values < $60 \mathrm{mg} / \mathrm{dL}$ showed no utility in AF differentiation, coinciding as described in the literature [23]. Moreover, the AMI ( $>100$ $\mathrm{IU} / \mathrm{L})$ showed no utility in differentiating AF. In this regard, the literature refers to the measurement of AMI in AF is useful for detecting ascites of pancreatic origin, and rarely can rise in non-pancreatic tumors [24].

FAL, TG and CK did not allow differentiating exudates from transudates. Thus we recommend the use of a new cutoff of cells $\left(>300 / \mathrm{mm}^{3}\right)$ to improve detection of exudate ascites. It is proposed to incorporate the ratio $\mathrm{AF} / \mathrm{S}$ for transaminases and especially for AST, with the purpose of optimizing the differentiation and characterization of the exudate ascites, together with the ratios for $\mathrm{LDH}$ and $\mathrm{PT}$.

SAAG reserves as a marker of portal hypertension associ- 
ated with cirrhosis.

\section{Conclusions}

We suggested the utilization of a new cutoff of cellular counting, major of $300 / \mathrm{mm}^{3}$, since it would allow improving the detection of exudate ascites, without including the cases of transudate ascites. Of the biochemical parameters studied, AST AF/S showed major usefulness in the differentiation and characterization of AF; LDH, PT, COL, and ALT might be also acceptable in the above mentioned differentiation. The SAAG turned out to be a good marker of portal hypertension associated with cirrhotic processes. The GLU and AMI did not show usefulness in the discrimination between transudates and exudates.

\section{Conflicts of Interest}

The authors report no conflicts of interest.

\section{References}

1. Runyon BA. Care of patients with ascites. N Engl J Med. 1994;330(5):337-342.

2. Burgess LJ. Biochemical analysis of pleural, peritoneal and pericardial effusions. Clin Chim Acta. 2004;343(12):61-84.

3. Rovelstad RA, Bartholomew LG, Cain JC, Mc KB, Soule EH. Ascites. I. The value of examination of ascitic fluid and blood for lipids and for proteins by electrophoresis. Gastroenterology. 1958;34(3):436-451.

4. Runyon BA, Montano AA, Akriviadis EA, Antillon MR, Irving MA, McHutchison JG. The serum-ascites albumin gradient is superior to the exudate-transudate concept in the differential diagnosis of ascites. Ann Intern Med. 1992;117(3):215-220.

5. Light RW, Macgregor MI, Luchsinger PC, Ball WC, Jr. Pleural effusions: the diagnostic separation of transudates and exudates. Ann Intern Med. 1972;77(4):507-513.

6. Ligth RW- Pleural diseases, 4th edition. Philadelphia: Lippincott Williams y Wilkins; 2001.

7. Boyer TD, Kahn AM, Reynolds TB. Diagnostic value of ascitic fluid lactic dehydrogenase, protein, and WBC levels. Arch Intern Med. 1978;138(7):1103-1105.

8. Hoefs JC. Serum protein concentration and portal pressure determine the ascitic fluid protein concentration in patients with chronic liver disease. J Lab Clin Med. 1983;102(2):260-273.

9. Pare P, Talbot J, Hoefs JC. Serum-ascites albumin concen- tration gradient: a physiologic approach to the differential diagnosis of ascites. Gastroenterology. 1983;85(2):240244.

10. Al-Knawy BA. Etiology of ascites and the diagnostic value of serum-ascites albumin gradient in non-alcohol liver disease. Ann Saudi Med. 1997;17(1):26-28.

11. Beg M, Husain S, Ahmad N, et al. Serum/Ascites Albumin Gradient in Differential Diagnosis of Ascites. Journal of Indian Academy of Clinical Medicine. 2001;2:51-54.

12. LeBlanc K, Arnold RM. Evaluation of malignant ascites \#176. J Palliat Med. 2010;13(8):1027-1028.

13. Weinstein L, Cibas S; Cytopathology of effusions (pleural, pericardial, and ascites). In: Atlas of Diagnostic Cytopathology. Barbara F, Alkinson. Edited by 2. Editorial Elseiver. 2004;105-118.

14. Prieto M, Gomez-Lechon MJ, Hoyos M, Castell JV, Carrasco D, Berenguer J. Diagnosis of malignant ascites. Comparison of ascitic fibronectin, cholesterol, and serum-ascites albumin difference. Dig Dis Sci. 1988;33(7):833-838.

15. World Medical Association Declaration of Helsinki: ethical principles for medical research involving human subjects. JAMA. 2013;310(20):2191-2194.

16. Rocher AE, Blanco AM, Palaoro LA. [Usefulness of AgNOR technique in the interpretation of serous effusions]. Rev Med Chil. 2000;128(9):963-968.

17. Rocher AE, Guerra F, Rofrano J, Angeleri A, Canessa OE, Mendeluk GR, Palaoro LA. Sensitivity and specificity of cytodiagnosis of body fluids in a laboratory of urgencies. Biotech Histochem. 2011;86(5):326-332.

18. Gupta R, Misra SP, Dwivedi M, Misra V, Kumar S, Gupta SC. Diagnosing ascites: value of ascitic fluid total protein, albumin, cholesterol, their ratios, serum-ascites albumin and cholesterol gradient. J Gastroenterol Hepatol. 1995;10(3):295-299.

19. Rana SV, Babu SG, Kocchar R. Usefulness of ascetic fluid cholesterol as a marker for malignant ascites. Med Sci Monit. 2005;11:136-142.

20. Seth AK, Rangarao R, Pakhetra R, et al. Accuracy of serum - ascites albumin gradient in the a etiological diagnosis of ascites. MJAFI. 2002;58:124-126.

21. Akriviadis EA, Kapnias D, Hadjigavriel M, Mitsiou A, Goulis J. Serum/ascites albumin gradient: its value as a rational approach to the differential diagnosis of ascites. Scand J Gastroenterol. 1996;31(8):814-817.

22. Elis A, Meisel S, Tishler T, et al. Fluid to serum bilirrubin concentration ratio for the classification of transudates or exudates. Am J Gastroenterol. 1998;138:1103-1105.

23. Runyon BA, Hoefs JC. Ascitic fluid chemical analysis before, during and after spontaneous bacterial peritonitis. Hepatology. 1985;5(2):257-259.

24. Runyon BA. Amylase levels in ascitic fluid. J Clin Gastroenterol. 1987;9(2):172-174. 